\title{
Computed tomography colonography in elderly patients, a safe and accurate colonic examination
}

\author{
Authors: Neel Raja, Michael Adeleye, Ajay Verma and Bhavini Billimoria
}

\section{Introduction}

In Kettering General Hospital we perform almost 500 computed tomography colonograms (CTCS) annually for patients who, do not want, are unable to tolerate, or have failed a colonoscopy (which is considered the 'gold standard' colonic examination). The most common reasons for CTC are iron-deficiency anaemia and change in bowel habit, often with the aim of detecting colorectal cancer (CRC).

We have seen an increase over time in the use of CTC in elderly patients as a first-line investigation. With an ageing population, we explore the significance of performing this examination in an elderly population who may not be suitable for further investigation/intervention.

\section{Methods}

We reviewed 1,479 patients who had undergone a CTC between October 2015 and October 2018. Of these, we focused on patients aged $\geq 80$ at the time of scanning. CTC reports were analysed and categorised into those with positive and indeterminate findings, and those with no significant findings. All patients $\geq 80$ years old were followed up (via their electronic records) to observe their outcomes.

\section{Results and discussions}

During the 3-year period 1,479 patients underwent a CTC. Fourhundred and fifty-four patients were aged $\geq 80$ years $(30.7 \%)$ (mean and median age, 84 years, range $80-97$ ). Sixty-nine patients had positive colonic findings (15.2\%, Fig 1) of which, 31 had CRC reported ( 14 operated straight away, 5 had endoscopy then surgery, 1 had endoscopy only (no tumour seen), 11 were not operated on). Twenty-two had polyps reported (13 had endoscopy at which 12 had polypectomy, 9 did not have endoscopy). Sixteen had indeterminate findings (10 had endoscopy which nil significant found).

Of the 385 patients who had CTCs with nil significant colonic findings, 9 had extra colonic tumours. At follow up (105 patients in 12 months from October 2015, 137 patients in 2016-17, 143 patients in 2017-18, range $0-36$ months), none of the patients have been diagnosed with CRC thus far.

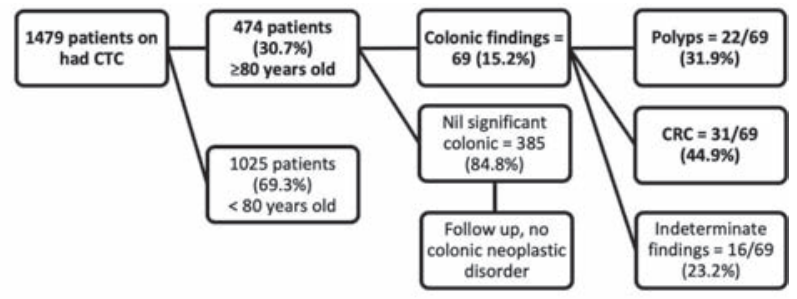

$\mathrm{CRC}=$ colorectal cancer $; \mathrm{CTC}=$ computed tomography colonogram

Fig 1. Summary of results $C R C=$ colorectal cancer; $C T C=$ computed tomography colonogram

\section{Conclusion}

In this study, CTC was used in elderly patients aged $\geq 80$ years old as a first- or second-line colonic examination. The yield of diagnosing colorectal cancer was $6.9 \%$ (31/454). CTC that reported negatively for colonic findings seems to protect patients for 0-36 months.

While colonoscopy may be the preferred diagnostic test for colonic disease, it is an invasive test with a small risk of perforation. CTC is safer, and better tolerated. The reports are generally accurate with regards to significant colonic findings, especially when diagnosing CRC. This study does confirm the safety and efficacy of CTC and suggests that it is an appropriate colonic investigation for elderly patients (aged $\geq 80$ years old) first- or second-line.

\section{Conflict of interest statement}

None declared. 